\title{
Classroom Automation System
}

\author{
Mrs. Tanuja Sali, \\ Department of Information Technology \\ Pimpri Chinchwad College of Engineering \\ Mr. Chetan Pardeshi, \\ Department of Information Technology \\ Pimpri Chinchwad College of Engineering \\ Mr. Vikas Malshette, \\ Department of Information Technology \\ Pimpri Chinchwad College of Engineering \\ Mr. Akshay Jadhav, \\ Department of Information Technology \\ Pimpri Chinchwad College of Engineering \\ Mr. Vishal Thombare \\ Department of Information Technology \\ Pimpri Chinchwad College of Engineering
}

\begin{abstract}
The application of Internet of Things in the modern world is the center of interest of many researchers and standardization bodies since several years. Internet of things mainly consists of two parts automations and analysis. Automation is an important topic which is more and more covered by various actors in the intelligent transportation systems, home automations field via many proposed solutions. Thus, in order to achieve the dream of automation, a special attention has given to the treatment of home automations and home management problem; especially when it comes to operating things with the help of mobile applications. In this context systems based on wireless operational technologies, are proposed to address this situation. Therefore, with increasingly high-speed networks, it is increasingly important to have mechanisms that keep throughput high. Our systems will certainly contribute to the concept of home automation and classroom automation is some way. The paper will present the complete adaptation of the new methodologies of the intelligent classroom automation systems. We will also present a schema of the proposed model
\end{abstract}

KEYWORDS - RFID, IOT, ATTENDANCE, NODEMCU

\section{INTRODUCTION}

It is expected that by 2020 there will be 50 million things that will be connected to the internet which was only about 15 million in 2010. In the internet of things home automation contributes to around $27 \%$ roughly. Revenue in the home automation sector amounts to US \$ $3759 \mathrm{~m}$ in 2016. In Spring 2015 Icontrol Networks surveyed 1,600 consumers for smart home report. The report suggests that in just 12 months there was seen a rise in the level of excitement about smart home with millennials (79\%) and parents $(76 \%)$ leading the pack and 50\% of the overall population excited about the technology. Apart from this the intent to purchase smart home technology is quickly following suit with $50 \%$ of people saying they plan to buy at least one smart home product in the next year.

In this system we will be focusing on classroom automation. It is observed in colleges that are taking the attendance and keeping a track record of the attendance is a major issue. We still follow the traditional method of a pen and paper attendance and even if there is some automation there needs to be more than one add on modules that make the system working. Companies and corporate offices follow the card swipe methods which is very useful to some extent. But when it comes to classroom attendance the things have still not changed. In today's time there are applications available that operate things with the help of RFID's. But we tend to set up a system which can operate the basic functions of taking the attendance of a class with the help of a mobile application. Expected application will have an inbuilt algorithm in the application that will figure out the 
attendance of the student. Cross verification of this can also be done with the help of options available that can help reduce the error rate. The system is also expected to provide a secured access to only the authorized people in the vicinity or the institute.

This system is also expected to solve the problem of incorrect attendance marked in the class intentionally or unintentionally. This system will generate accurate count for each person with a tag through an algorithm without any biases. This said system model is proposed for the basic automations for a classroom that need to be automated. This system is also expected to help automate classroom electronics such as tube light, fan etc. If changes incorporated further this can also help in contributing to the institute automation and make the entire information of the place available in a single mobile application with the help of GPS tracking. This will also help in having a good automation impact in the near future for city and home automations . This will also add as an initiative to digitalize the world and make a smarter move towards the evolution of Internet of Things.

\section{BACKGROUND INFORMATION}

Counting to 315 million students, India has the most number of students in the world. This counts that there is a strong need for the automation when it comes to mark the attendance of these students. $69.133 \%$ of the total youth are found college going or taking some kind of education. The traditional system which is being followed since ages is the pen and paper method. Later we observe a time wherein to avoid the intentional fake attendance given by the student's adoption of biometric system was observed. Colleges have started to turn down to this in order to say goodbye to intentional proxy attendances, apart from this when it comes down classroom automation we also need to consider the electric equipments and their functioning. We have a strong need of a system where it can mark attendance along with a regular thing (say ID card). Hence these systems will be not only help in attendance but also make things like ID cards compulsory for college premises. A classroom mostly consist of a fan and a tube light at least. Many a times it is observed that it's the human nature and we tend to forget to switch off the lights when we leave the house. This leads to more of energy consumption and wastage of energy. The same scenario can also happen with the classroom. Hence it is considered as one of the most important issue that needs to be addressed. The same system is not only dedicated to solve the problems of class room but the same can also be used in home automation application. The said system can be used to keep a track on the devices that are on in the classroom when we are not present. This will lead to automation plus the energy consumption factor that will save energy. The system will operate with the help of a relay module. The relay controls the circuit functions and acts as an interface between input and output circuits. The system will also require a communication network channel that helps to transmit messages between the application at the user end and the hardware at the system end.

\section{PRoposed SysteM-}

The proposed system is a union of hardware components like relay modules, voltage supplies NODEMCU and softer components like mobile applications. Both are equally important and don't any importance in the system without each other's existence. The system is divided into 2 parts for better understanding.

A - The electrical equipments automation.

B - Attendance automation part.

\section{A] The electrical equipments automation-}

The initial phase of this will consist of a mobile application that takes care of the end user. This system of application is soulfully designed only for the user end (in case of classroom automation it will be designed for teachers). The application will require a signup at the beginning which is only for one time. Mandatory fields will be the registered email address of the teacher with the institute and the identification id (UID or the employee id). These will important if in case the password or the other fields need to be reset. In the next phase after successful registration there will be a login page that will have a username and password as the input fields. If the password is forgotten and needs to be reset there will be a field which will help to reset the password. After successful login there will be options available to perform the respective operations i.e. Lights Fans and Attendance. Lights and fans automation is explained in this part and figure 1.1 explains the detailed architecture of the proposed system. 


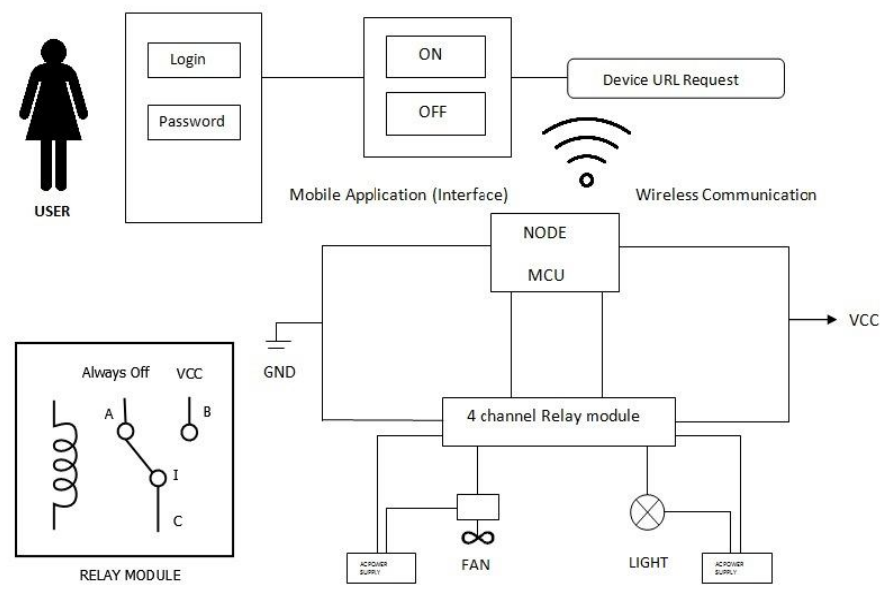

Figure 1.1:Electrical Equipment's automation

In this module, the user performs operations on light and fan. And these operations like ON or OFF. This task will be performed by NodeMCU kit and user will give his request through android application. The mobile application will have a login page in which the user is expected to enter his credentials.

After successful login process user can actually perform the operation on these devices by selecting device type means light or fan and select operation type. Suppose user select device type as light and operation type as ON. When user sends request of LIGHTON then this request will send using Device URL request to NodeMCU through wireless communication network. In wireless communication there are two ways first is using router and second is, by creating hotspot. NodeMCU is an open source IoT platform. The NodeMCU firmware is a companion project to the popular NodeMCU dev kits. NodeMCU module provides access to the GPIO(General Purpose Input/Output) subsystem. All access is based on the I/O index number on the NodeMCU dev kits, not the internal GPIO pin. For example, the D0 pin on the dev kit is mapped to the internal GPIO pin 16 and GPIO (General Purpose Input/Output) refers to a set of generic pins of a microcontroller that can be used for digital signaling. GPIO pins can be individually set to act as input or output, and values can be either logically high (1) or low (0). The voltage value is ideally set to VCC for high and GND for low. But, the underlying technology determines the actual acceptable logic levels.

This NodeMCU and relay module is connected to each other. The both VLC pins of NodeMCU and relay are connected to each other and GND pins of both devices are also connected to each other. The nature of relay module is always off when request will received via NodeMCU that time relay's circuit will become opened and device will act according to user's request means light will become ON.

\section{B] Attendance automation part -}

In this module the student attendance is automated with the help of Radio Frequency Identification (RFID) Technology. Each student will be provided with a RFID card for identification purpose and the uniqueness of this system is that student's college identity card will be printed itself on RFID card thus making it compulsory for student to bring his college identity card. A RFID card has its internal storage which holds a unique identification number. These cards can be programmable or comes with a predefined identifier. This RFID card/tag is a passive tag which will be activated when in contact with a RFID receiver. The card contains at least two components: an integrated circuit for storing the unique identification number and modulating and demodulating radio frequency (RF) signals; an Antenna for signal sending and receiving purpose. The RFID readers are fixed and they create an interrogation zone. It reads the RFID cards/tags when they go in or out of the interrogation zone. The reader gets a unique identification number from RFID card. RFID receiver is connected with a microcontroller Arduino NodeMCU ESP8266 module. The NodeMCU is an IoT platform. It is a firmware that uses Lua scripting language. The unique identification number read by reader is collected by the microcontroller kit and it will be sent on a static web page then it will be 
compared in the SQLite database of dedicated Android application for this system. The SQLite database is weakly typed, ACID compliant database. It does not uses client-server architecture like most of the databases. It resides on local/client side or can be embedded in applications or web browsers. This also provides bindings with an android application. If the unique identification number is matched with any record in database the associated record of student will be retrieved from database and the information will be stored in another database and that student's attendance will be marked and will be notified to the teacher via the android application. In case of attempt to mark intentional fake attendance if any student marks attendance of other students, the system also stores total count of number of students who marked their attendance then the teacher can cross verify headcount of students by entering value in application and can have detailed information of present students and students who are absent but still having their attendance marked.

The diagrammatic schema of this system is explained in detail in the below figure 1.2

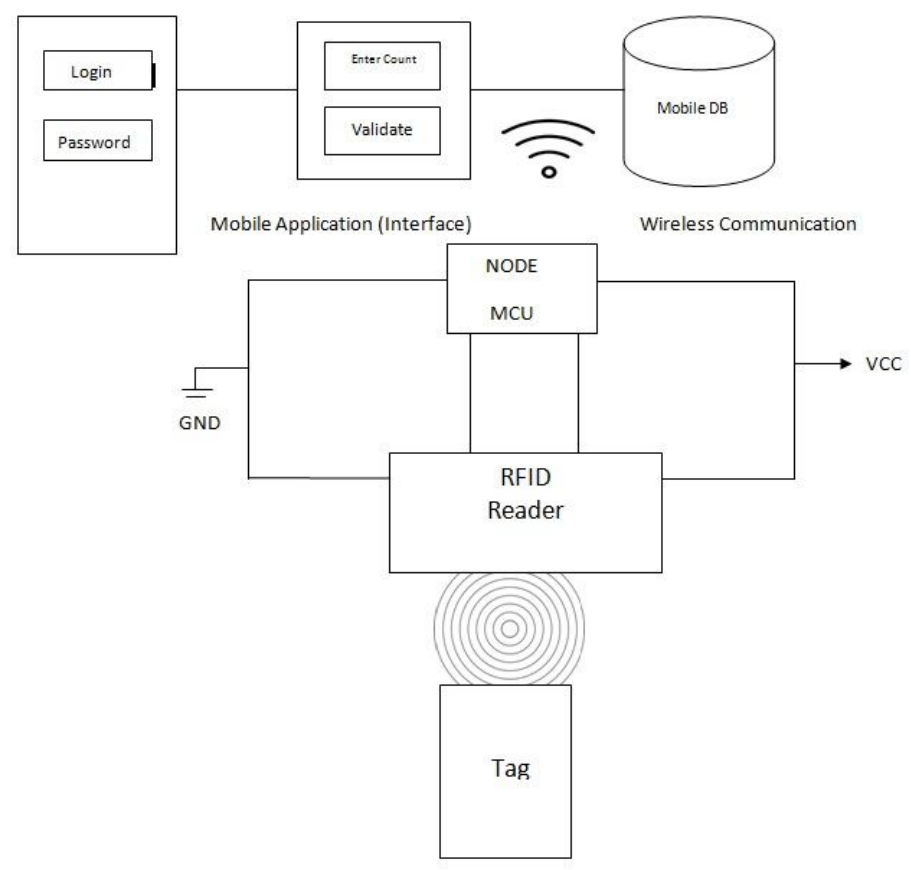

Figure 1.2:Attendance Automation Part

Algorithm-

Assume the following things

i- Pre-established wireless communication network.

ii- A NodeMCU which is capable of performing the expected operations.

iii- A RFID set in working condition.

iv- Assume all connections set and are working

Step 1: The user logins into the system using the username and password.

Step 2: Select any one option from given menu

-Lights

-Fans 
-Attendance

Step 3: Click the ON/OFF button (On clicking the lights and fans button the URL below that button will be triggered and the operations are performed)

Step 4: Validating the attendance has an option of entering the headcount. If the headcount matches with the tags tapped at the RFID reader then information is fed in else the operation gets failed.

For every operation that is done there is an exit button available which can help in quitting the transaction directly.

\section{EVALUATION OF THE SYSTEM}

As per stated in the background information the automation of classrooms along with the very important attendance is covered in this proposed system. The said system is expected to validate the present people in the classroom and the entries done with the help of RFID. This addresses the problem when there are questions raised on multiple people using the same tag. This helps in identifying the problem and correcting where it is going wrong. The system can be evaluated on the basis of how efficient it is in giving the list of the students who are present for a given lecture. The liability can be verified by manually checking the test instances for a couple of times. Moving on with the other electrical components that are automated with the help of the same mobile application also have to be evaluated. As discussed in the architecture part these components will be connected to various different equipment's. Hence it becomes necessary to check all the connections in the hardware. If all the components are in place they will function well and give the desired output. Running the system everyday will make the data load heavy in the database hence it is required to check the working of the database at regular intervals.

\section{CONCLUSION AND FUTURE RESEARCH DIRECTIONS}

This presents a model that has been proposed to meet the basic needs of classroom automation. An important advantage of this system is that it gives the system as a complete prototype to develop more such cost efficient systems that can be used in classrooms and college automation. A study of the system shall be conducted in order to verify the expected results in the classroom automation system as proposed.

In addition to this the future work can be focused on developing applications that can help in automating an entire department or a college. Future work should be along the lines of considering the validation of the attendance also by including an image detection technique which will further more authenticate the person.

The same model also can be helped in making a home automation system which will be cost efficient. Different technological advances can help in making the system more reliable.

\section{ACKNOWLEDGMENTS}

Our thanks to the experts who have contributed towards development of the paper.

\section{REFERENCE}

[1] Shweta Singh, Kishore Kumar Ray, HOME AUTOMATION SYSTEM USING INTERNET OF THINGS [2] Renewable Energy Based Home Automation System Using ZigBee, Archana N. Shewale, Jyoti P. Bari

[3] L. Coetzee and J. Eksteen, -The internet of things - promise for the future? an introduction, $\|$ in IST-Africa Conference Proceedings, 2011, May 2011, pp. 1-9.

[4] M. L. Michael Chui and R. Roberts, -The internet of things,| http://www.mckinsey.com/insights/high-techtelecoms-internet/theinternet-of-things, 2010.

[5] D. Wang, Y. Murase, and K. Sugiura, -Design and implementation of user-centered home appliance controlling service environment, $\|$ in Proceedings of Workshop on Mobile Video Delivery 
[6] M. Schwartz, Home Automation with Arduino: Automate your Home using Open-Source Hardware. Create Space Independent Publishing Platform, July 2013.

[7] F.Viani, F.Robol, A.Polo, P.Rocca, G.Oliveri and A.Massa, "Wireless Architecture for Heterogeneous Sensing in Smart Home Applications: Concepts and Real Implementation," Proceedings of IEEE, vol.101, pp.2381-2396, July 2013.

[8] https://nodemcu.readthedocs.io/en/master/

[9] https://github.com/nodemcu/nodemcu-firmware/ 